\title{
O labelling approuch: do plano teórico à realidade fática
}

\author{
Edvania Fátima Fontes Godoy ${ }^{1}$
}

\begin{abstract}
"Tem fé no direito, como o melhor instrumento para a convivência humana; na justiça, como destino normal do direito; na paz, como substitutivo bondoso da justiça; e, sobretudo, tem fé na liberdade, sem a qual não há direito, nem justiça, nem paz".
\end{abstract}

Eduardo Couture

\section{Resumo}

\begin{abstract}
As transformações pelas quais o mundo passou na década de 60 funcionaram como um fermento para a ruptura do pensamento até então predominante, o que possibilitou o desenvolvimento da teoria do labelling approuch, sendo esta a principal responsável pelo surgimento da Criminologia crítica. O labelling approuch, também entendido por etiquetamento, rotulagem ou paradigma da reação social, desloca o problema criminológico do plano da ação para o da reação, demonstrando, assim, que a característica comum entre os delinqüentes é a resposta das agências de controle social.
\end{abstract}

Palavras-Chave: Ruptura do pensamento; Labelling approuch; Controle social.

\section{Introdução}

Com enfoque na Teoria Labelling Approuch é possível verificar que a repressão estatal tem natureza classista e hierárquica, sendo, inclusive, a responsável pela "invenção" dos crimes e conseqüente criação dos criminosos.

O Labelling Approuch, também entendido por Paradigma da Reação Social, ergueuse do Interacionismo Simbólico, o qual evidencia que não é possível a análise da natureza humana ou da sociedade como dados fixos, imutáveis. Baseando-se no pensamento sistêmico, defende o entendimento de que as qualidades, os defeitos, enfim, o comportamento dos indivíduos perante a sociedade, não são qualidades intrínsecas e, portanto, só podem ser compreendidas dentro do contexto da totalidade do corpo social.

É possível que se entenda o Paradigma da Reação Social com a simples identificação de três níveis: o primeiro, investiga o impacto da atribuição do status de delinqüente na

1 Graduada em Direito pela Universidade Filadélfia de Londrina - UNIFIL e Pós-Graduanda em Direito Penal e Processo Penal pela Universidade Estadual de Londrina - UEL. 
identidade do indivíduo, é o que se conhece por desvio secundário. O segundo, investiga o processo de atribuição do status de criminoso, também podendo ser compreendido como processo de seleção. E por fim, o terceiro, que investiga o processo de definição da conduta desviada ou criminalização primária. Através destas constatações, tal teoria visa demonstrar que o sistema penal atua elegendo os candidatos à criminalização.

Dessa forma, este estudo, em síntese, busca atentar para a necessidade de se repensar o sistema penal no seu todo, no contexto de uma sociedade aberta, democrática e pluralista, ampliando-se as margens de tolerância para superação dos conflitos e das tensões sociais, utilizando-se, para tanto, de novas alternativas.

\section{0 surgimento do labelling approuch}

A partir da década de 60 do século passado, assistiu-se a um processo de desconstrução e deslegitimação teórica do sistema penal, bem como, de seus paradigmas, o que acabou por gerar a desconstrução dos modelos penais fundamentais. Interessante dizer, nesse sentido, que este impulso desestruturador ${ }^{2}$ não tem suas bases em um pronunciamento isolado no campo penal, visto que, insere-se no contexto da radicalização social, política, cultural e, sobretudo, na intensa explosão de conflituosidade que dominaram essa época, ou seja, o momento de crise do Estado providência nas sociedades do capitalismo avançado (ANDRADE, 1997, p. 182).

A desconstrução interacionista do labelling approuch, por sua vez, insere-se na chamada primeira dimensão do impulso desestruturador, posição esta, que acabou proporcionando a descoberta das intenções mais secretas dos modelos penais fundamentais. Em linhas gerais, neste processo de conversão, transformou-se o próprio estatuto do saber criminológico, pois tal conversão se deu através da desconstrução e superação do paradigma etiológico ${ }^{3}$ pelo paradigma da reação social, processo este, que ocasionou o surgimento da Criminologia crítica (ANDRADE, 1997, p. 184).

2 A expressão "impulso desestruturador" deve ser compreendida nas suas duas dimensões: a dimensão desconstrutora consubstanciada pela critica historiográfica, sociológica e criminológica do moderno sistema penal e a dimensão das Políticas Criminais alternativas e dos movimentos de reforma que a ela se seguiram e somente puderam ser pensados a partir dessa desconstrução (ANDRADE, 1997, p. 183).

3 Etiologia é o estudo sobre a natureza, a origem, a causa das coisas (BUENO, 2000, p. 334). 
Observa-se, na verdade, que não é a prática de um delito que determina a vulnerabilidade de uma pessoa frente ao poder punitivo, nem sequer é uma condição necessária para ser objeto da seleção criminalizante, senão suas características pessoais, ou seja, as que invariavelmente pertencem às classes carenciadas, sua juventude e seu sexo, visto que, os indivíduos que habitam as prisões são, na maioria das vezes, pobres, jovens e varões. Estas são as características comuns dos estereótipos criminais, às quais se agregam também a outros estereótipos e finalmente acabam associadas a condições culturais, políticas, geográficas, etc, (ZAFFARONI, 1991, p. 16-17, tradução nossa).

De resto, o que mais chama atenção é a forte oposição do labelling approuch frente ao princípio da igualdade, em cujo âmbito se demonstra que o desvio e a criminalidade não são identidades preconstituídas e concebidas como tendo uma natureza comum, que é inerente a todos e a cada um dos seres, visíveis através da ação das distintas instâncias do sistema penal, mas pelo contrário, são uma qualidade atribuída a determinados sujeitos por meio de mecanismos oficiais e não-oficiais de definição e seleção. Assim, impossível estudar a criminalidade sem a análise destes processos. A partir do ponto de vista das definições legais, a criminalidade se revela como o comportamento da maioria, antes que de uma minoria desviada da população (ANDRADE, 1997, p. 202).

\subsection{Interacionismo simbólico ${ }^{4}$ e construtivismo social modelando o paradigma epistemológico do labelling approuch}

Na opinião de Zaffaroni (2001, p. 60) "a função deslegitimante mais importante e irreversível do discurso jurídico penal tem sido realizada pelo interacionismo simbólico, que fundamentou a criminologia da reação social". A principal base desta corrente pode ser delimitada, de forma muito ampla, pela afirmativa de que cada um dos indivíduos se torna aquilo que os outros vêem e, desta forma, a prisão desempenha o papel de reprodutora, ou seja, o individuo rotulado como delinqüente acaba finalmente assumindo a função que lhe é consignada e, consequentemente, comportando-se de acordo com ela.

\footnotetext{
A expressão "interação simbólica" foi concebida por Herbert Blumer em 1937. Indica um ramo da sociologia e da psicologia social que se concentra em processos de interação. Tal visão parte da idéia segundo a qual as relações sociais em que as pessoas estão inseridas as condicionam reciprocamente. As relações sociais, então, não surgem como determinadas de uma vez por todas, mas como abertas e dependendo de constante aprovação em comum (SHECAIRA, 2004, p. 289).
} 
A máquina do sistema penal, como se sabe, está pronta para esse etiquetamento e, principalmente, para o reforço desses papéis. Em linhas gerais, essa teoria da rotulação, do etiquetamento social, juntamente com as contribuições do interacionismo e da fenomenologia, mostram a indiscutível primazia da descrição pormenorizada, sem nenhum enfeite teórico, do chamado processo de produção e reprodução da delinqüência (ZAFFARONI, 2001, p. 60).

O labelling approuch carrega em suas bases duas grandes tendências: uma radical e outra moderada. Enquanto a primeira eleva a função constitutiva ou criadora da criminalidade, atribuída ao controle social, para o qual o crime não passa de uma etiqueta que as instituições de controle social informal colocam no desviado, independentemente, de sua conduta ou merecimento, a segunda, sem obstáculo, parte do pressuposto que a justiça penal integra a mecânica do controle social geral da conduta desviada (MOLINA; GOMES, 2002, p. 388).

A perspectiva criminológica interacionista conduziu, por outro lado, ao reconhecimento de que o estudo e o controle da criminalidade requerem, no mais alto grau, um approuch integrado do processo de efetivação da justiça penal. Por tal motivo, é visto como um processo dinâmico e coerente, dotado de um objetivo social e operando num contexto de mudança social. As modificações operadas em uma das partes do sistema afetam necessariamente o que ocorre em outras, condicionando em medida larga, ou mesmo decisiva, a resposta total (DIAS; ANDRADE, 1997, p. 373).

Para Baratta (1999, p. 87), é segundo o interacionismo simbólico que a realidade social se constitui através de uma infinidade de interações concretas entre os indivíduos, aos quais um processo de tipificação atribui uma qualificação que se afasta das situações concretas e continua a expandir-se através da linguagem. Por sua vez, de acordo com a etnometodologia, a sociedade não é uma realidade que se possa compreender no plano objetivo e, sim, o produto de uma construção social, obtida mediante um processo de definição e tipificação por parte de indivíduos e grupos diversos. Portanto, no enfoque do interacionismo e da etnometodologia, estudar a realidade social, neste caso o desvio, significa imprescindivelmente, estudar tais processos, iniciando-se dos que são aplicados a simples comportamentos e chegando às construções mais complexas, como a concepção da própria ordem social. 
Como se sabe, a Criminologia tradicional se preocupa com questões do tipo: quem é criminoso?, como se torna desviante?, em quais condições um condenado se torna reincidente?, com que meios pode se exercer controle sobre o criminoso?. Ao invés destas indagações, os interacionistas, principalmente aqueles que se inspiram no labelling approuch, se questionam: quem é definido como desviante?, que efeitos decorrem desta definição sobre o indivíduo?, em que condições este indivíduo pode se tornar objeto de uma definição?, e, por fim, quem define quem? (BARATTA, 1999, p. 88).

Desta forma, a pergunta relativa à natureza do sujeito e do objeto, no conceito obtido pelo comportamento desviante, impulsionou a pesquisa dos teóricos do labelling approuch em duas direções: a primeira, conduziu ao estudo da formação da identidade desviante, e do que se define como desvio secundário, sendo este último, o efeito da efetiva aplicação da etiqueta de criminoso; a segunda direção, por sua vez, conduziu ao problema da definição, da constituição do desvio como qualidade atribuída a indivíduos e comportamentos durante a interação, conduzindo, também, para o problema da distribuição do poder de definição, ou seja, o estudo dos que detém o poder de definição em grande proporção na sociedade, as agências de controle social (BARATTA, 1999, p. 89).

\section{0 labelling approuch}

O labelling approuch é designado na literatura alternativa e sinonimicamente, por enfoque (perspectiva ou teoria) do interacionismo simbólico, etiquetamento, rotulação ou ainda por paradigma da reação social, do controle ou da definição (ANDRADE, 1997, p. 186).

H. Becker é considerado o fundador desta perspectiva criminológica, sobretudo através de seu livro Outsiders, publicado em 1963 e, permanecendo, até os dias de hoje, como a principal obra do labelling approuch (ANDRADE, 1997, p. 186).

Ao labelling approuch, deve-se o mérito exclusivo e indiscutível pela ampliação do objeto da investigação criminológica, ao frisar a importância da ação muito seletiva e discriminatória das instâncias e mecanismos de seleção responsáveis pelo controle social. Indo mais além, pois em razão deste enfoque interacionista, já não se pode mais estudar e compreender o problema criminal dispensando a própria reação social e, consequentemente, o processo social de definição e de seleção de certos indivíduos e condutas rotuladas como delitivas. Deve-se também ao labelling, uma explicação bem mais 
realista do dogma tradicional da igualdade diante da lei e um louvável interesse pelo problema da desviação secundária e das carreiras criminais (MOLINA; GOMES, 2002, p. 389).

Ao enfatizar que o crime não é o objeto e, sim, o produto da reação social, considerando-se que cada indivíduo é livre na sua essência, não sendo a criminalidade uma característica inerente aos rotulados e, sobretudo, ao mostrar que o crime não está imbuído de natureza social e definitorial, o etiquetamento realça o papel do controle na construção social, evidenciando que as agências controladoras não detectam ou declaram a natureza criminal de um comportamento, ao contrário, a produzem ao rotulá-la assim (ANDRADE, 1997, p. 206).

Desse modo, é possível deduzir à luz da Criminologia dialética ou crítica, que o Direito Penal é considerado como um dos instrumentos do controle social, selecionando e diferenciando de forma desigual os bens e interesses jurídicos a serem tutelados por via da incriminação das condutas desviantes que ataquem ou coloquem em perigo os interesses da classe econômica dominante (FERNANDES; FERNANDES, 2002, p. 469).

É de se dizer, que as expressões "conduta desviante" ou "desvio social" utilizadas pelos teóricos do interacionismo, na maioria das vezes, alcançam ações relativas à ofensa e à violação de bem jurídico tutelado pela lei penal de determinado país. Sobre essa questão, interessante perceber as diferenças existentes, por exemplo, de um país para outro: no Brasil, atualmente, diferencia-se o traficante do usuário de drogas, fato que é recente em nossa legislação, em Amsterdã, no entanto, o uso de drogas é liberado, ao contrário da Argentina, onde são radicalmente punidas as condutas de tráfico e de uso (ANDRADE, 1997, p. 186).

Ainda nessa linha de intelecção, pode-se dizer que as questões relativas à natureza do objeto e do sujeito na formação dos comportamentos desviantes orientaram o surgimento de três níveis elucidativos do labelling approuch (ANDRADE, 1997, p. 208):

a) um nível orientado para a investigação do impacto da etiqueta de criminoso na identidade do desviante, o que gera o comportamento conhecido por desvio secundário. Evidencia-se que a intervenção do sistema penal, especialmente a prisão, ao invés de oferecer um efeito reeducativo sobre o delinqüente, acaba por determinar, na maior parte dos casos, a consolidação de uma verdadeira e própria carreira criminal, lançando luz sobre o problema não resolvido da reincidência e dos efeitos criminógenos do tratamento penal; 
b) um nível orientado para a investigação do processo de atribuição do status criminal, da etiqueta, ou seja, a forma de aplicação das normas penais pela polícia e pela justiça, que pode ir desde a simples rejeição social até a reclusão do delinqüente. Para o labelling approuch este é um momento fundamental não só para a construção seletiva da criminalidade, mas, também, pelos seus efeitos na identidade do rotulado;

c) um nível orientado para a investigação do processo de definição da conduta desviada, também conhecido por criminalização primária, conseqüente do problema da distribuição do poder social, isto é, de quem detém em maior ou menor medida este poder na sociedade, recaindo, ao final, sob o processo de criação das normas penais. É o momento em que se definem os bens jurídicos a serem protegidos, as condutas criminalizadas, a qualidade e quantidade das penas. Contudo, não se limitam à análise das definições legais, levando também em conta as definições informais produzidas pelo público em geral.

Como se depreende, a investigação se transferiu dos controlados aos controladores e, voltando-se a uma dimensão macrossociológica, para o poder de controlar (ANDRADE, 1997, p. 209).

Em consonância com o acatado, oportuno se torna mencionar as palavras de Molina e Gomes (2002, p. 374), "a teoria do labelling approuch contempla o crime como mero subproduto do controle social". Pressupõe-se, assim, que o indivíduo transforma-se em delinqüente não pela realização de uma conduta negativa, mas sim pelo fato de determinadas instituições sociais formais e informais o rotularem como tal, consagrando, desta forma, um status de delinqüente que as referidas instituições de controle espalham de forma seletiva e discriminatória.

Sob esse aspecto, leciona Zaffaroni (2001, p. 133): "Nossos sistemas penais reproduzem sua clientela por um processo de seleção e condicionamento criminalizante que se orienta por estereótipos proporcionados pelos meios de comunicação em massa". De acordo com ele, os órgãos do sistema penal são responsáveis pela seleção segundo os estereótipos criados pelos meios de comunicação em massa, em conseqüência disso, acabam atribuindo e exigindo tais comportamentos como se assim o fossem, contudo, vão mais além, pois instigam todos a enxergar do mesmo modo.

Como é comum, nem todos os indivíduos respondem a esta astúcia humana da mesma forma. O estereótipo, como se sabe, alimenta-se das características gerais dos 
setores majoritários mais despossuídos e, não obstante a seleção ser preparada desde cedo na vida do indivíduo, é ela mais ou menos arbitrária. Os sujeitos que se mostram mais sensíveis às demandas do papel formuladas pelas agências dos sistemas penais são os mais imaturos, considerando-se estes, aqueles que possuem menor independência a respeito de sua adequada distinção em relação aos objetos externos. Verifica-se que a maior sensibilidade às demandas do rótulo relaciona-se diretamente com a possiblidade de invasão que o indivíduo ofereça (ZAFFARONI, 2001, p. 134).

De igual forma, quando assume o rótulo demandado pelos órgãos penais, "o indivíduo converte-se em importante colaborador para a manutenção do sistema penal" (ZAFFARONI, 2001, p. 134). Por tais razões, sem a contradição derivada deste comportamento imposto, o sistema penal não seria uma ilusão e, sim, uma grande alucinação, a qual seria muito mais difícil de ser provocada.

Convém ponderar que a carga estigmática não é provocada pela condenação formal, mas sim, pelo simples contato com o sistema. Os meios de comunicação de massa têm enorme contribuição para esta carga, visto que, difundem fotografias e quase sempre se adiantam quanto às sentenças utilizando-se de qualificações como "vagabundos", "chacais", dentre outras (ZAFFARONI, 2001, p. 134).

Paradoxalmente, este fenômeno não é privativo do sistema penal, contudo, nele assume características particulares: "uma pessoa começa a ser tratada 'como se fosse', embora não haja manifestado nenhum comportamento que implique uma infração". No momento em que se generaliza o tratamento de acordo com o "como se fosse" e está atribuição social é sustentada quase sem exceção durante o tempo, o indivíduo passa a se comportar com referência no papel que the foi atribuído e, com isso, acaba "sendo" (ZAFFARONI, 2001, p. 134).

Como se há de verificar, a seleção recrutadora dos agentes e operadores dos órgãos judiciais ocorre, na maioria das vezes, entre os setores médios e médios-baixos da população, contudo, ocasionalmente, tal seleção pode se dar entre as pessoas da classe média alta. O processo de criminalização é escancaradamente elitista, incriminando preferencialmente condutas típicas das classes sociais baixas e privilegiando ou contemporizando os comportamentos das classes mais elevadas. Há uma distorção ideológica da tarefa criminológica, promovida pela ação oficial e pelos meios de divulgação 
de opinião pública, distorção que, execrando o criminoso convencional, serve de vedação para acobertar e até justificar, por exemplo, carcinomas sociais do tipo do "colarinho branco" (FERNANDES; FERNANDES, 2002, p. 469).

Por tais razões, para Baratta (1999, p. 86), o "labelling approuch tem se preocupado principalmente com as reações das instâncias oficiais de controle social, consideradas na sua função constitutiva em face da criminalidade". Indubitável é, sob este foco, o efeito estigamatizante da atividade da polícia, dos órgãos de acusação, dos juízes e das instituições penitenciárias.

Os representantes do labelling approuch acreditam que o que distingue a criminologia tradicional da nova sociologia criminal é a consciência critica com relação à definição do próprio objeto (a "criminalidade", o "criminoso") da investigação criminológica, sendo que este objeto deve ser encarado como uma realidade social que não se apresenta como pré-constituída à experiência cognoscitiva e prática, e sim, construída dentro desta experiência, conforme os processos de interação que a caracterizam. Assim temos, que tal realidade deve ser compreendida de forma critica em sua construção (BARATTA, 1999, p. 86).

É bem verdade que inúmeros autores censuram o interacionismo simbólico, alegando, para tanto, que se trata de uma teoria de médio alcance, incapaz de revelar-se macrossociologicamente. Acreditam que a crítica à prisão, por exemplo, não é capaz de superar o nível de crítica ao pessoal penitenciário. Embora tal observação seja procedente, tal limitação não consegue subtrair valor à deslegitimação realizada pelo interacionismo. Em outras palavras, não há dúvidas de que haja limitações na teoria, contudo, ela necessita apenas ser completada, visto que seus resultados são verdadeiros. "Do ponto de vista da desqualificação do discurso jurídico-penal, a 'rotulação', por ser menos discutível, tem maior poder desqualificante" (ZAFFARONI, 2001, p. 61).

Seja como for, é certo que as teorias da criminalidade baseadas no labelling approuch guiaram a resultados irreversíveis. Em certos aspectos, estas teorias sacudiram os fundamentos da ideologia penal tradicional, principalmente, o denominado princípio da igualdade, visto que, demonstrou-se que a criminalidade, segundo a sua definição legal, não é o comportamento de uma minoria, e sim, o da maioria dos cidadãos e que, de acordo com sua definição sociológica, é um status atribuído a determinados indivíduos por parte 
daqueles que detêm o poder de instituir e aplicar a lei penal, mediante mecanismos seletivos, sobre cuja estrutura e funcionamento a estratificação e o antagonismo dos grupos sociais têm uma influência fundamental (BARATTA, 1999, p. 113).

Em síntese, a teoria do labelling approuch se coloca criticamente com relação ao princípio da prevenção ou do fim, e em particular face à ideologia oficial do sistema penitenciário atual: a ideologia da ressocialização. Valendo contemplar, ainda, que ao recorrer à diferença entre desvio primário e secundário, as teorias da criminalidade construídas com base no labelling approuch contribuíram para a crítica dos sistemas de tratamento, com um princípio teórico fundamental para esta crítica, que explicita não só os efeitos criminógenos do tratamento penal como também atenta para o problema não resolvido da reincidência (BARATTA, 1999, p. 114).

\section{A sociedade e o crime}

A noção de uma igualdade humana dentro de determinada sociedade, é radicalmente falsa. A desigualdade social é a responsável pelas situações de conflito, que na maioria das vezes, terminam em criminalidade, entendendo-se esta como todos os atos que constituem infração penal (FERNANDES; FERNANDES, 2002, p. 51).

Evidencie-se, que o crime é produto de dois fatores: o "criminoso" e a sociedade, sendo que cada um possui sua própria ação, que por sua vez, será fator determinante na sucessão da criminalidade, que ao final, assumirá os mais diversificados aspectos em função de cada um deles (FERNANDES; FERNANDES, 2002, p. 52).

Acredita-se que a prática de crimes é a responsável pela exclusão social dos indivíduos, mas é o contrário, a exclusão social é que oportuniza condições para que o indivíduo reporte-se ao caminho do crime. A partir do momento em que um indivíduo defronta-se com o preconceito, a discriminação, a falta de oportunidades, e todas as demais formas de exclusão, as normas de conduta social perdem o sentido para ele, não há mais motivos para acatá-las, ocorre um antagonismo, passando, então, a conviver e agir de acordo com os membros do grupo ao qual participa, tal fato se dá, inclusive, por uma questão de sobrevivência. A reinserção social do encarcerado não terá como condição sua readequação ética, mas, pelo contrário, sua readequação ética é que terá como condição sua reinserção social (SÁ, 2005, p. 26). 
Com propriedade, vaticina Christie (1998, p.13):

O crime não existe. É criado. Primeiro existem atos. Seguem-se depois um longo processo de atribuir significado a esses atos. A distância social tem importância particular. A distância aumenta a tendência de atribuir a certos atos o significado de crimes, e às pessoas o simples atributo de criminosas.

Nessa esteira, o policial, o juiz, o legislador, mesmo sendo frequentemente indagados quanto às suas práticas pessoais e coletivas, são, na maioria das vezes, vistos como representantes da ordem e, consequentemente, do bem. Por sua vez, os delinqüentes, ao contrário dos referidos representantes do sistema, são vistos pela sociedade como pertencentes a uma espécie aparte, são anormais sociais que, nesse sentido, deveriam ser facilmente identificáveis, já que não seriam como os outros (HULSMAN, 1993, p. 57).

Ante o exposto, verifica-se que as condições gerais que determinam a aplicação da definição de desvio, dentro do senso comum, ou seja, a atribuição de responsabilidade moral e uma reação correspondente, são: um comportamento que se distancie dos modelos das normas estabelecidas; um indivíduo que, se tivesse desejado, poderia ter agido de forma diferente, ou seja, de acordo com o disposto nas normas; e um indivíduo que tinha plena consciência de sua conduta. Nessa conjuntura, as categorias presentes na atribuição de responsabilidade moral e de desvio criminal, na esfera do senso comum, correlacionam-se exatamente às três categorias construídas pela ciência jurídica, determinando, assim, a imputação de um delito a determinado indivíduo, "segundo o pensamento jurídico: violação da norma, consciência e vontade". Contudo, "este processo de atribuição não pode ser confundido com um processo de descrição", erro que muitas vezes se comete na realidade (BARATTA, 1999, p. 96).

\subsection{Criminalização primária e criminalização secundária}

Em sentido estrito, criminalidade ou delinqüência é a qualidade inerente à determinada ação ou omissão anti-social, imbuída de natureza delituosa. Já em sentido lato, considera-se criminalidade os fenômenos anti-sociais que abrangem um conjunto de delitos em suas várias modalidades, durante certa época e em cada região ou lugar (SOARES, 2003, p. 55). 
Na verdade, é imprescindível mostrar as culpabilizações artificiais que este sistema produz. A experiência do processo e do encarceramento, na maioria dos casos, provoca nos condenados um estigma que pode se tornar profundo. As definições legais e a rejeição social por elas produzida podem criar no indivíduo uma percepção através da qual ele realmente se considere um desviado e, assim, passe a agir de acordo com esta imagem. Como se sabe, o sistema penal cria o criminoso, todavia, imperativo frisar, que tal criação se dá em um nível muito mais grave do que se imagina: o nível da interiorização do estigma legal e social pelo indivíduo atingido (SOARES, 1993, p. 69).

Na visão do detento, o sofrimento da prisão é o preço a ser pago por um ato que uma justiça gélida e inconseqüente colocou numa balança desumana, ao passo que, quando for posto em liberdade, o preço pago terá sido tão alto, que apesar do sentimento de quitação, o indivíduo passará a agir de uma outra forma, motivado por sentimentos de ódio e agressividade. "O sistema penal endurece o condenado, jogando-o contra a 'ordem social' na qual pretende reintroduzi-lo, fazendo dele uma outra vítima" (SOARES, 1993, p. 72).

Os comportamentos desviantes reincidentes à reação social, que compreendem a incriminação e a pena, são basicamente decorrentes dos efeitos psicológicos que tal reação produz no individuo. Essa conduta desviada nada mais é do que um meio de defesa, de ataque ou de adaptação aos problemas apresentados ou ocultados pela reação social com relação ao primeiro desvio (BARATTA, 1999, p. 90).

Para a construção e a compreensão de uma teoria da criminalidade baseada no labelling approuch, é imprescindível que se dê destaque a distinção entre desvio primário e desvio secundário, visto que, tal linha de pesquisa, coloca em dúvida o princípio do fim ou da prevenção e, em particular, a concepção reeducativa da pena (BARATTA, 1999, p. 90).

É sobremodo importante assinalar, que enquanto o desvio primário se alude a um contexto de fatores sociais, culturais e psicológicos, que por sua vez, não se centram sobre a base psíquica do indivíduo e, consequentemente, não conduzem por si mesmos a uma reorganização da atitude que o indivíduo tem para consigo mesmo, e do seu papel social, os desvios sucessivos à reação social, englobando a compreensão da incriminação e da pena, são estruturalmente determinados pelos efeitos psicológicos que tal reação produz no indivíduo objeto da mesma (BARATTA, 1999, p. 90). 
Posta assim a questão, é de se dizer, que na verdade, esses resultados mostram que a intervenção do sistema penal, principalmente no que se refere às penas detentivas, antes de terem um efeito reeducativo sobre o indivíduo, determinam, na maior parte dos casos, uma consubstanciação da identidade desviante do condenado e o seu efetivo ingresso em uma real e própria carreira criminosa (BARATTA, 1999, p. 90).

Neste passo, conclui-se que a desviação primária é poligenética e se deve a uma variedade de fatores culturais, sociais, psicológicos e sociológicos, ao contrário, da desviação secundária, que pode ser traduzida como uma resposta de adaptação aos problemas ocasionados pela reação social e pela desviação primária (SHECAIRA, 2004, p. 306).

\subsection{Aspectos do controle social}

No âmbito da sociologia de progênie norte-americana a expressão controle social é habitual desde o início do século XX. Entende-se, que toda sociedade ou grupo social, necessita de mecanismos disciplinares que garantam a convivência interna de seus membros, motivo pelo qual se vê obrigada a viabilizar uma gama de instrumentos formais e informais que asseverem a conformidade dos objetivos escolhidos no plano social (SHECAIRA, 2004, p. 55).

É sobremodo importante assinalar que quando as instâncias informais de controle social falham, entram em ação as agências de controle formais. Em síntese, se o indivíduo, frente ao processo de socialização, não possui um comportamento plausível com os modelos de conduta transmitidos e aprendidos na sociedade, entrarão em ação as instâncias formais que exercem seu controle de forma coercitiva, instituindo sanções qualitativamente distintas das reprovações existentes na esfera informal (SHECAIRA, 2004, p. 56).

Irrefragável é, ainda, a função estigmatizante deste controle, desencadeando desviações secundárias e carreiras criminais. O verdadeiro resultado do controle social formal é muito menor do que o resultado obtido pelas instâncias do controle informal, o que esclarece, por exemplo, o fato de ser a criminalidade muito maior nos grandes centros urbanos do que nas pequenas comunidades, onde se têm um controle informal mais efetivo e presente (SHECAIRA, 2004, p. 56).

Nesta linha de intelecção, vale lembrar que a teoria do controle social baseia-se no princípio pelo qual a ordem estabelecida em determinada sociedade ou em determinado 
grupo humano procura assegurar a obediência de seus membros através de padrões de comportamento, sendo esses de natureza jurídica, moral, política, econômica, ideológica, filosófica, religiosa, literária, artística, e assim por diante, tudo corroborado com os interesses das classes economicamente fortes e politicamente dominantes. Cumpre ratificar, que é nesse arcabouço que se encontra a problemática da criminalização, ou melhor, os critérios relacionados às ações e omissões humanas consideradas anti-sociais, delituosas, enfim, sujeitas à repressão penal (SOARES, 2003, p. 49).

Por outro enfoque, verificada a amplitude e pluridimensionalidade do controle social, que pode se dar tanto formal quanto informalmente, constata-se que o controle é exercido pelo sistema penal de forma que "dentro do controle social a norma penal, o sistema jurídico-penal, ocupa um lugar secundário, puramente confirmador e assegurador de outras instâncias muito mais sutis e eficazes" (ANDRADE, 1997, p. 211).

Por derradeiro, cumpre asseverar que no plano do controle social punitivo as diferenças entre as instâncias de controle social informais são evidentes se comparadas ao controle social formal exercido pela esfera estatal. Este último é seletivo e discriminatório, preterindo o status sobre o merecimento (SHECAIRA, 2004, p. 291).

\subsubsection{Sistema prisional}

A visão e o pensamento que se tem com relação à prisão, na maioria das vezes é puramente abstrata, colocando-se em primeiro lugar a ordem, o interesse geral, a segurança pública e a defesa dos valores sociais. Todavia, tal visão não passa de uma ilusão absurda. Privar um indivíduo de sua liberdade não é uma coisa à toa, além do enclausuramento o indivíduo é também, muitas vezes, submetido a castigos corporais. A prisão degrada os corpos. A privação de ar, de sol, de luz, de espaço, o confinamento entre as grades, a prosmicuidade com companheiros de forma indesejada, em condições higiênicas humilhantes, dentre tantas outras provações físicas, só servem para acentuar, agredir e deteriorar o corpo e a mente (HULSMAN, 1993, pp. 61 - 62).

Ao perder a liberdade, aquele que tinha um emprego e vivia de seu salário, imediatamente perde o emprego, ao passo que, perde também a possibilidade de manter sua casa e arcar com as despesas da família. Passa a identificar-se separadamente desta família, com todos os problemas morais que isto acarreta: esposa ou companheira aturando 156

ReVISTA de DiReito PúBlico, LondRINA, V. 2, N. 1, P. 143-164, JAN./ABR. 2007. 
as forças hostis dos vizinhos e conhecidos, filhos marcados pelo estigma advindo da prisão do pai, que por sua vez, tendo sido bruscamente cortado do mundo, experimenta um total distanciamento de tudo que conheceu e amou (HULSMAN, 1993, p. 62).

Desta forma, o condenado à prisão adentra em um ambiente alienante, onde todas as relações são deformadas no âmago. Além da privação da liberdade, a prisão acarreta inúmeras outras seqüelas ao indivíduo, que penetra num mundo não natural, onde tudo é restritivo. As regras de vida na prisão fazem prevalecer relações de passividadeagressividade e de dependência-dominação, que de forma consideravelmente generalizada não deixam espaço para a iniciativa e o diálogo, são hábitos que incentivam o desprezo pela pessoa, aumentando o isolamento interior, visto que, o ambiente de opressão desvaloriza a auto-estima, fazendo desaparecer a comunicação autêntica com o próximo e impedindo a construção de atitudes e comportamentos socialmente aceitáveis para quando chegar o dia da libertação. "Na prisão, os homens são despersonalizados e dessocializados" (HULSMAN, 1993, p. 63).

Estatui Zaffaroni (2001, p. 136), que a prisão ou cadeia é uma instituição com comportamento verdadeiramente deteriorante, da qual decorre uma patologia cuja essencial peculiaridade é a regressão. O prisioneiro é levado para condições de vida que nada tem a ver com as de um adulto, sendo privado e limitado de fazer tudo o que um adulto usualmente faz. Ademais disso, é ferido na sua auto-estima de todas as formas possíveis, seja através da perda de privacidade, da perda de seu próprio espaço ou das constantes submissões e revistas degradantes. Somam-se a esses fatores, as precárias e deficientes condições de quase todas as prisões: superlotação, alimentação paupérrima, falta de higiene e assistência sanitária, isso sem contar as discriminações pela falta de condições para pagar por alojamentos e comodidades.

O "efeito da prisão, que se denomina prisionização, sem dúvida, é deteriorante e submerge a pessoa numa 'cultura de cadeia', distinta da vida do adulto em liberdade" (ZAFFARONI, 2001, p. 136). Esta ocultação cultural não pode ser vista como uma tentativa de reeducação ou algo próximo disso, visto que, suas formas de realização são totalmente divergentes a este discurso, o qual possui um caráter escamoteador, podendo, inclusive, ser visto pelos menos informados. 
Interessante mencionar, que embora a prisão seja sempre deteriorante, é possível confirmar que nem sempre o resultado é eficiente no que tange à reprodução de clientela. Como se sabe, as diferentes formas de sensibilidade às exigências do rótulo dependem da maturidade do sujeito que, se não conseguir distinguir claramente os limites de seu mundo exterior, será rapidamente corrompido pelas restrições desse meio. O fruto dessa invasão, em um pequeno número de casos, acaba por causar um efeito desestruturante, do qual decorre a degeneração do indivíduo, que consequentemente, será direcionada à psicose ou ao suicídio; no entanto, em um número bem maior, o indivíduo se corromperá assumindo o rótulo de acordo com as exigências; por fim e, em um número bem pequeno de casos, o indivíduo resistirá e não se deixará danificar por nenhum dos dois sentidos acima referidos. Não se pode esquecer, que há alguns casos nos quais o sujeito, mesmo estando na prisão, não se auto-intitula como criminoso e, em decorrência disso, as exigências da etiqueta são diferentes (ZAFFARONI, 2001, p. 136).

Como se sabe, há um enorme esforço mundial em prol da redução da aplicação do sistema prisional, bem como, sua substituição por alternativas que possam representar a resposta penal para aquele que delinqüiu, sem, no entanto, remetê-lo ao cárcere. Desta forma, constata-se que o grande desafio do mundo moderno é reduzir ao máximo a aplicação da pena privativa de liberdade, reservando a prisão somente para aqueles realmente perigosos ou que não possam permanecer em liberdade (D'URSO, 1999, p. 68).

O Estado é responsável por aqueles que estão presos, de modo que tudo o mais, todas aquelas atrocidades sofridas pelo preso no período da segregação, são de responsabilidade direta do Estado. Contudo, apesar da possibilidade de indenização, como se poderá restituir o que foi perdido na prisão, à dignidade aniquilada é impossível de ser devolvida, o contato com o sistema deixa marcas na alma e no comportamento do indivíduo. Tendo em vista tal realidade, não há outra vertente senão mudar o eixo da política criminal brasileira, o que pode se dar através de um direito penal mínimo, com o qual a incidência do campo penal só ocorra quando todos os outros mecanismos de controle social falirem (BARATTA, 1999, p. 69).

Após o estudo do estigma da exclusão social, pertinente o esquadrinhamento das palavras de Oliveira (2006, p. 12): 
O preso ainda resta completamente ignorado pelos responsáveis pelas decisões acerca das políticas públicas, na medida em que não compõe o tão cobiçado eleitorado, não tem representatividade alguma nas esferas de poder. Seu alijamento político o coloca à margem dos direitos fundamentais da pessoa humana, não possuindo meios institucionalizados eficientes de vindicá-los.

Ainda neste sentido, é de se dizer, que são inúmeras as dificuldades enfrentadas por qualquer ex-presidiário que queira refazer sua vida, lamentavelmente, mesmo na administração ordinária de nossa justiça, uma vergonha radical e excludente acaba tornando-se parte da punição. Embora os "criminosos" tenham pago sua dívida com a sociedade, continuam manchados por uma aura de infâmia. O absurdo, é que esse tipo de vergonha também assola os negros, as minorias sexuais, os incultos, os miseráveis, e assim por diante, vive-se em uma sociedade individualista e excludente (CALLIGARIS, 2006, p. E8).

Quando a justiça falha, o convívio social fica ameaçado pela arbitrariedade. A punição não pode ser entendida como vingança contra o transgressor e, sim, como um meio de se fazer valer as normas do convívio social, visto que, sem estas, voltaríamos à barbárie. Desse modo, a reforma do sistema penitenciário é uma necessidade visível, todavia, seja por que razão for, tem sido sempre adiada ou empreendida sem a urgência que se faz necessária, o que acaba levando a opinião pública a reclamar da frouxidão da legislação penal e dos procedimentos dos órgãos do controle formal frente ao aumento da criminalidade (GULLAR, 2006, p. E12).

Sob esse aspecto, é indubitável e absolutamente visível que as prisões brasileiras não cumprem nenhuma de suas funções básicas, inclusive, também não recuperam quem cumpre a pena, pois se estima que $60 \%$ dos que saem acabam presos como reincidentes (e outros tantos continuam no crime impunemente), ou seja, o desvio secundário tratado pelo labelling approuch realmente ocorre na maior parte dos indivíduos alcançados pelo sistema prisional. Não obstante a isso, as prisões também não evitam que os presos continuem controlando o crime de dentro das cadeias. A inexistência de políticas públicas para o atendimento dos presos que pagam suas dívidas com a Justiça e retornam às ruas dispostos a levar uma vida digna, ajudam, sobretudo, a alimentar a criminalidade (AZEVEDO, 2006).

Cumpre ressaltar, que a maior parte da população prisional não oferece risco à sociedade, segundo dados de pesquisa realizada pelo Ministério da Justiça no ano de 2005, a 
maioria foi preso por furto $(9,1 \%)$, roubo $(23,9 \%)$, tráfico $(10,5 \%)$, homicídio $(8,9 \%)$ e outros crimes (47,6\%), (AZEVEDO, 2006).

O perfil dos presos brasileiros, como se vê, reflete a parcela da sociedade que fica fora da vida econômica. Retornando aos dados do Ministério da Justiça, no ano de 2005, constata-se que a população prisional trata-se de uma massa de pobres, jovens, não brancos e com pouca escolaridade. Entre eles, cerca de $70 \%$ não chegaram a completar o ensino fundamental, $10 \%$ são analfabetos, $60 \%$ têm entre 18 e 30 anos, 83 \% não estudam, 74 \% não trabalham e 30\% não recebem visitas (AZEVEDO, 2006).

Assim como a pena alternativa, o regime semi-aberto não funciona porque não há fiscalização suficiente. Verdade seja, que o difícil é convencer alguém que esteve sob a mira de um revólver de que o cárcere não é um remédio eficaz (AZEVEDO, 2006).

Em consonância com o acatado, importante se torna observar o perfil da população encarcerada segundo o censo penitenciário de 1997, que revela alguns dados interessantes: $48 \%$ dos presos são brancos, $30 \%$ mulatos e $17 \%$ negros. Na maioria dos casos, as pessoas foram presas por roubo, representando $34,01 \%$ dos crimes. A segunda causa mais comum é o homicídio com 16,02\%, seguida do tráfico de entorpecentes com 14,18\%. Registre-se, ainda, que os Estados que fazem fronteira com outros países e no Rio de Janeiro, o número de pessoas presas por tráfico é bem maior (GUERRA, 2005, p. 12).

Embora existam diversos programas implantados nas unidades prisionais do país para ressocialização dos presos, a experiência, assim como as pesquisas, comprova que não há eficácia na tão falada ressocialização, o que acaba tornando o sistema penitenciário na ponta final de todos os problemas sociais (GUERRA, 2005, p. 13).

Percebe-se que para esconder o comodismo e o descaso, há uma crença de que a ordem estabelecida no mundo atual é justa e cada um tem a vida que merece. A violência praticada e o tratamento dispensado contra os presos é sempre justificada pelo comportamento dos próprios encarcerados, como se eles realmente não prestassem e tivessem a obrigação de se redimir.

\section{Conclusão}

O Paradigma da Reação Social ergueu-se do Interacionismo Simbólico, evidenciando que não é possível considerar a natureza humana ou a sociedade como dados imutáveis. As 160

ReVISTA de DiReito PúBlico, LondRINA, V. 2, N. 1, P. 143-164, JAN./ABR. 2007. 
propriedades das partes não são, nesse sentido, intrínsecas e, portanto, só podem ser entendidas dentro do contexto da totalidade. Vale dizer, que a sociedade é produto da interação do comportamento de seus indivíduos, a partir da qual se estabelece uma rede contínua e inseparável de inter-relacionamentos.

É possível afirmar, que o Paradigma da Reação Social através de seu conteúdo epistemológico revolucionário, proporcionou o surgimento de uma nova forma de percepção do sistema penal, inclusive, expondo de forma extraordinária sua fragilidade.

Tal inovação na forma de compreensão do funcionamento do sistema penal motivou modernas indagações, as quais, conseqüentemente, ensejaram o surgimento da Criminologia crítica, dando ênfase aos novos objetos de estudo, ou seja, iniciou-se u ma preocupação com relação aos conteúdos ideológicos promovidos pelo sistema penal, passando-se a buscar explicações para este processo de refração da reação social.

Sendo assim, não se deve indagar os motivos pelos quais as pessoas se tornam criminosas, deve-se buscar explicações sobre os possíveis motivos que levam determinadas pessoas a serem estigmatizadas como delinqüentes, qual a fonte da legitimidade e quais as conseqüências da punição imposta a essas pessoas, atentando-se, sobretudo, para os critérios ou mecanismos de seleção das instâncias de controle social. Como se pôde observar, as carreiras criminosas negam a concepção reeducativa da pena e a ideologia do tratamento ao evidenciar que a intervenção do sistema penal, em especial da prisão, ao invés de exercer um efeito reeducativo sobre o delinqüente, determina, na maior parte dos casos, a consolidação de uma verdadeira e própria carreira criminal, lançando luz sobre os efeitos criminógenos do tratamento penal.

Nossa vida é livremente inventada e reinventada por nossos atos, portanto, nossos atos podem ser punidos, mas nunca deve ser punida e estigmatizada a nossa "essência".

Uma sociedade pode conviver em paz apesar de grandes dificuldades sociais e econômicas, mas à condição que ela não exclua e envergonhe uma parte de seus membros.

\section{Referências}

ANDRADE, Vera Regina Pereira de. A Ilusão da Segurança Jurídica: do controle da violência à violência do controle penal. Porto Alegre: Livraria do Advogado, 1997. 
AZEVEDO, Solange. Estudo da ONU e do Ministério da Justiça radiografa a bomba-relógio de 308 mil presos. Serviço Ecumênico de Militância nas Prisões - SEMPRI. 2006. Disponível em: $<$ http://sempri.blig.ig.com.br/>. Acesso em: 07 set. 2006.

BARATTA, Alessandro. Criminologia Crítica e Crítica do Direito Penal: introdução à sociologia do direito penal. Traduzido por Juarez Cirino dos Santos. 2. ed. Rio de Janeiro: Freitas Bastos, 1999.

BRASIL tem 361 mil atrás das grades. Agência Senado. Folha de Londrina, Londrina, 24 maio 2006, Caderno Geral, p. 8.

CALLIGARIS, Contardo. A vergonha de ser pobre. Folha de São Paulo, São Paulo, 23 fev. 2006, Folha llustrada, p. E8.

CHISTIE, Nils. A indústria do controle do crime. Traduzido por Luís Leiria. Rio de Janeiro: Forense, 1998.

DIAS, Jorge de Figueiredo. ANDRADE, Manoel da Costa. Criminologia: o homem delinqüente e a sociedade criminógena. 2. ed. Coimbra: Coimbra, 1997.

D’URSO, Luiz Flávio Borges. Direito Criminal na Atualidade. São Paulo: Atlas, 1999.

FERNANDES, Newton. FERNANDES, Valter. Criminologia Integrada. 2. ed. São Paulo: Revista dos Tribunais, 2002.

GARCIA, Antonio. MOLINA, Pablos de. GOMES, Luiz Flávio. Criminologia. 5. ed. São Paulo: Revista dos Tribunais, 2006.

GUERRA, Layla. Sistema Carcerário: uma triste realidade. Revista MPD Dialógico, São Paulo, v. 2 , n. 05 , p. 10,13 . maio/junho de 2005.

GULLAR, Ferreira. Crime e Castigo. Folha de São Paulo, São Paulo, 6 ago. 2006, Folha llustrada, p. E12.

HULSMAN, Louk. Penas Perdidas: O Sistema Penal em Questão. Trad. Maria Lúcia Karam. 2. ed. Niterói: Luam, 1993.

OLIVEIRA, Fábio Rocha de. Preso Cidadão: Os Direitos Políticos do Criminalmente Condenado. Boletim IBCCRIM, São Paulo, v. 13, n. 160, p. 12. Disponível em: $<w w w . i b c c r i m . c o m . b r>$. Acesso em: 13 mar. 2006. 
QUINTANILLA, Miguel Angel. Breve Dicionário Filosófico. Traduzido por Laura Nair Silveira Duarte. 2. ed. Aparecida: Santuário, 1996.

SÁ, Alvino Augusto de. A "Readequação" Ética da Conduta dos Encarcerados e sua Reinserção Social: Proposta de uma Inversão das Relações. Revista MPD Dialógico, São Paulo, v. 2, n. 05, p. 26, maio/jun. 2005.

SHECAIRA, Sérgio Salomão. Criminologia. São Paulo: Revista dos Tribunais, 2004.

SOARES, Orlando. Curso de Criminologia. Rio de Janeiro: Forense, 2003.

ZAFFARONI, Eugenio Raúl. Em Busca das Penas Perdidas: a perda da legitimidade do sistema penal. Traduzido por Vânia Romano Pedrosa e Amir Lopez da Conceição. Rio de Janeiro: Revan, 1998.

. No hay Derecho. Cuadernos de la Cárcel: Edição especial. Buenos Aires, 1991. 
